\title{
Quality of survival after severe birth asphyxia
}

\author{
ALISON J. THOMSON, MARGARET SEARLE, AND G. RUSSELL \\ From Aberdeen Maternity Hospital and the Royal Aberdeen Children's Hospital
}

SUMMARY Thirty-one children who survived severe birth asphyxia defined by a 1-minute Apgar score of 0 , or a 5-minute Apgar score of $<4$, have been seen at age 5 to 10 years for neurological and psychological assessment. Their progress has been compared with that of controls matched for sex, birthweight, gestational age, and social class. $29(93 \%)$ of the 31 asphyxiated group and all the controls had no serious neurological or mental handicap. 2 were severely disabled and mentally retarded. Detailed studies of psychological function showed no significant differences between the two groups. 2 apparently stillborn infants have made normal progress. It was not possible to identify any perinatal factor which predicted the occurrence of serious handicap with certainty. We considered that the quality of life enjoyed by the large majority of the survivors was such as to justify a positive approach to the resuscitation of very severely asphyxiated neonates.

Perinatal asphyxia is a major cause of morbidity and mortality in the first week of life. The survivors have long been recognized to have an increased risk of handicaps such as cerebral palsy, mental retardation, epilepsy, deafness, visual impairment, and disorders of learning and behaviour in later childhood. With modern advances in perinatal care a reduction in the prevalence of handicap in surviving children is anticipated.

The Apgar score (Apgar, 1953) is widely accepted as a means of assessing the severity of birth asphyxia. Several studies have shown a significant correlation between low Apgar scores at 1 minute (Drage et al., 1966; Richards et al., 1968; Dweck et al., 1974) and at 5 minutes (Drage et al., 1966) and the incidence of neurological abnormality in survivors. Drage et al. (1966) found that the 5-minute Apgar score gave a better differentiation than the 1-minute score in this respect. Most published studies to date report the neurological and psychological status in preschool children who were asphyxiated at birth as assessed by low Apgar scores at either 1 or 5 minutes of age. Studies of school age children are required to assess fully the extent to which birth asphyxia impairs their capacity to learn.

This study was undertaken to determine the neurological and psychological progress of a group of children now aged 5-10 years, who suffered severe birth asphyxia as assessed by an Apgar score of 0 at 1 minute or $<4$ at 5 minutes of age. Their outcome is compared with that of a control group.

Received 18 December 1976

\section{Patients and methods}

Cases. In 1964-68 inclusive there were 14890 singleton live births to mothers living in the city and suburbs of Aberdeen of whom $14373(96.5 \%)$ were delivered in the Aberdeen Maternity Hospital and its associated maternity homes. Of these 14373 infants, 4 had a 1-minute Apgar score of 0 and 82 had a 5-minute Apgar score of $<4$. The cases examined in this study are the 2 survivors out of the 4 with a 1-minute score of 0 , and 29 of the 41 survivors with a 5-minute score of $<4$. Incomplete follow-up data are available on 9 further children.

The mode of delivery and intrapartum complications of these 31 cases are shown in Table 1 . In 28 cases the Apgar scores were recorded by a trained member of the paediatric staff and in 3 by the obstetrician or midwife responsible for the delivery. The time taken to achieve sustained spontaneous respiration, recorded in 29 infants, ranged from $5 \frac{1}{2}$ to 60 minutes with a mean of 14 minutes. All infants received intermittent positive pressure ventilation, 26 via endotracheal tube, 4 viá mask, and 1 by mouth-to-mouth until regular spontaneous respiration was established. One infant was ventilated from birth until 6 hours of age and another for a 24-hour period. Both survivors with a 1-minute Apgar score of 0 had no vital signs at birth. In one case the fetal heart was absent for 10 minutes before delivery; in the other it was last recorded at 116/min 5 minutes before birth. After external cardiac massage the apex beat was present in both infants by 5 minutes of age. 2 further infants had cardiac arrests, both of 
Table 1 Mode of delivery and intrapartum complications

\begin{tabular}{|c|c|c|c|}
\hline & Case & $\operatorname{ses}(n=31)$ & Controls $(n=29)$ \\
\hline Caesarean section & 9 & $\left\{\begin{array}{l}3 \text { uterine dys- } \\
\text { function } \\
2 \text { ruptured uterus } \\
1 \text { placenta praevia } \\
1 \text { cord prolapse } \\
1 \text { accidental } \\
\text { haemorrhage } \\
1 \text { compound } \\
\text { presentation }\end{array}\right.$ & 0 \\
\hline Forceps & & $\begin{array}{l}\text { (all vertex; } \\
1 \text { Kielland's) }\end{array}$ & 2 (vertex) \\
\hline $\begin{array}{l}\text { Spontaneous vaginal } \\
\text { delivery }\end{array}$ & & $\begin{array}{l}\text { ( } 3 \text { rapid delivery of } \\
\text { head) }\end{array}$ & $\begin{array}{l}27 \text { (1 rapid delivery } \\
\text { of head) }\end{array}$ \\
\hline $\begin{array}{l}\text { Intrapartum } \\
\text { pre-eclampsia }\end{array}$ & 3 & & 2 \\
\hline $\begin{array}{l}\text { Intrapartum } \\
\text { haemorrhage }\end{array}$ & 5 & & 0 \\
\hline $\begin{array}{l}\text { Clinical fetal distress } \\
\text { (fetal heart }<100 \text {, or } \\
>170 / \text { min }+ \text { /or } \\
\text { meconium staining) }\end{array}$ & 10 & & 1 \\
\hline
\end{tabular}

approximately 1 minute's duration. All cases were admitted to the Special Care Nursery where they received full supportive care.

Using the data of Thomson et al. (1968), 22 out of the 25 born after 37 completed weeks of pregnancy were of appropriate birthweight for gestational age, and 3 light-for-dates (<10th centile). Of the 6 preterm infants, 4 were of appropriate weight for gestational age and 2 light-for-dates. Although monitoring for asymptomatic hypoglycaemia was not an established practice at this time, none of the infants investigated had a blood sugar $<30 \mathrm{mg} /$ $100 \mathrm{ml}(1.7 \mathrm{mmol} / \mathrm{l})$. Apart from one case who developed neonatal intestinal obstruction due to biopsy-proven Hirschsprung's disease, there were no major congenital malformations. 6 infants were jaundiced but none had an indirect serum bilirubin concentration of $>13 \mathrm{mg} / 100 \mathrm{ml}(220 \mathrm{mmol} / \mathrm{l})$. The number of cases exhibiting various abnormal postnatal behavioural features is given in Table 2 .

Controls. For 29 of the 31 cases a control infant matched for sex, birthweight $( \pm 250 \mathrm{~g})$, gestational

Table 2 Abnormal postnatal behaviour

\begin{tabular}{|c|c|c|c|c|}
\hline \multirow[b]{2}{*}{ Feature } & \multicolumn{3}{|c|}{$\begin{array}{l}\text { No. of cases exhibiting } \\
(n=31)\end{array}$} & \multirow{2}{*}{$\begin{array}{l}\text { No. of controls } \\
\text { exhibiting } \\
(n=29)\end{array}$} \\
\hline & Total & $\begin{array}{l}\text { No serious } \\
\text { handicap }\end{array}$ & $\begin{array}{l}\text { Serious } \\
\text { handicap }\end{array}$ & \\
\hline $\begin{array}{l}\text { Need for tube feeding } \\
\text { (inappropriate for } \\
\text { gestational age) }\end{array}$ & 4 & 2 & 2 & 0 \\
\hline $\begin{array}{l}\text { Apnoeic + /or } \\
\text { cyanotic attacks }\end{array}$ & 8 & 7 & 1 & 2 \\
\hline Convulsions & 4 & 2 & 2 & 0 \\
\hline $\begin{array}{l}\text { Hypothermia } \\
\quad\left(\text { temp }<35^{\circ} \mathrm{C}\right)\end{array}$ & 5 & 3 & 2 & 0 \\
\hline $\begin{array}{l}\text { Cerebral cry } \\
\text { Abnormal muscle tone }\end{array}$ & $\begin{array}{l}5 \\
6\end{array}$ & $\begin{array}{l}3 \\
4\end{array}$ & $\begin{array}{l}2 \\
2\end{array}$ & $\begin{array}{l}\mathbf{0} \\
\mathbf{0}\end{array}$ \\
\hline
\end{tabular}

age ( \pm 2 weeks), and social class was taken from the same population by using the first consecutive hospital unit number which fulfilled these criteria. By so selecting, the mean difference in chronological age between cases and controls was $2 \cdot 7$ weeks (range 0-14 weeks). All controls had an Apgar score of 8,9 , or 10 at both 1 and 5 minutes of age, and established regular spontaneous respiration within the first minute of life. Mode of delivery and intrapartum complications are given in Table 1, and postnatal behaviour summarized in Table 2 .

The sex and the mean values for birthweight, gestational age, and age at study of cases and controls are given in Table 3.

Table 3 Mean values for birthweight, gestational age, and age at study

\begin{tabular}{llll}
\hline & $\begin{array}{l}\text { Cases } \\
(n=29)\end{array}$ & $\begin{array}{l}\text { Controls } \\
(n=29)\end{array}$ & Mean difference per pair \\
\hline Birthweight (g) & 3010 & 3040 & 110 \\
Gestational age (w) & $39 \cdot 6$ & $39 \cdot 3$ & $0 \cdot 4$ \\
Age at study (yr) & $8 \cdot 11$ & $8 \cdot 25$ & $0 \cdot 20$ \\
\hline
\end{tabular}

29 pairs: 20 male, 9 female.

Neurological assessment. A full history of developmental progress, behaviour, and the occurrence of convulsions was taken from one or both parents. The school medical records were examined with particular reference to vision and hearing testing, speech defects, and behaviour difficulties. Neurological examination was based on the methods described by Paine and Oppé (1966). Visual acuity was tested using the Stycar 7-letter card (Sheridan, 1960) in the few children in whom it had not already been recorded by a consultant ophthalmologist or school medical officer. Hearing was tested using the Stycar Picture Vocabulary test (Sheridan, 1958) when the results of pure tone audiometry performed by the school health service were not available.

At the completion of the neurological examination each child was given an overall rating on a 4-point scale according to the presence and severity of neurological abnormality and the resulting physical handicap (Rutter et al., 1970). Category 1 No abnormal neurological findings. Category 2 Neurological findings of slight or doubtful significance. Category 3 Definite disorder, but producing little or no physical handicap. Category 4 Definite and obviously handicapping neurological disorder.

Psychological assessment. The Illinois Test of Psycholinguistic Ability (ITPA) (Kirk et al., 1961) and the Bender-Gestalt Test (Bender, 1946) were used in the assessment by a psychologist who was unaware of which children were cases and which 


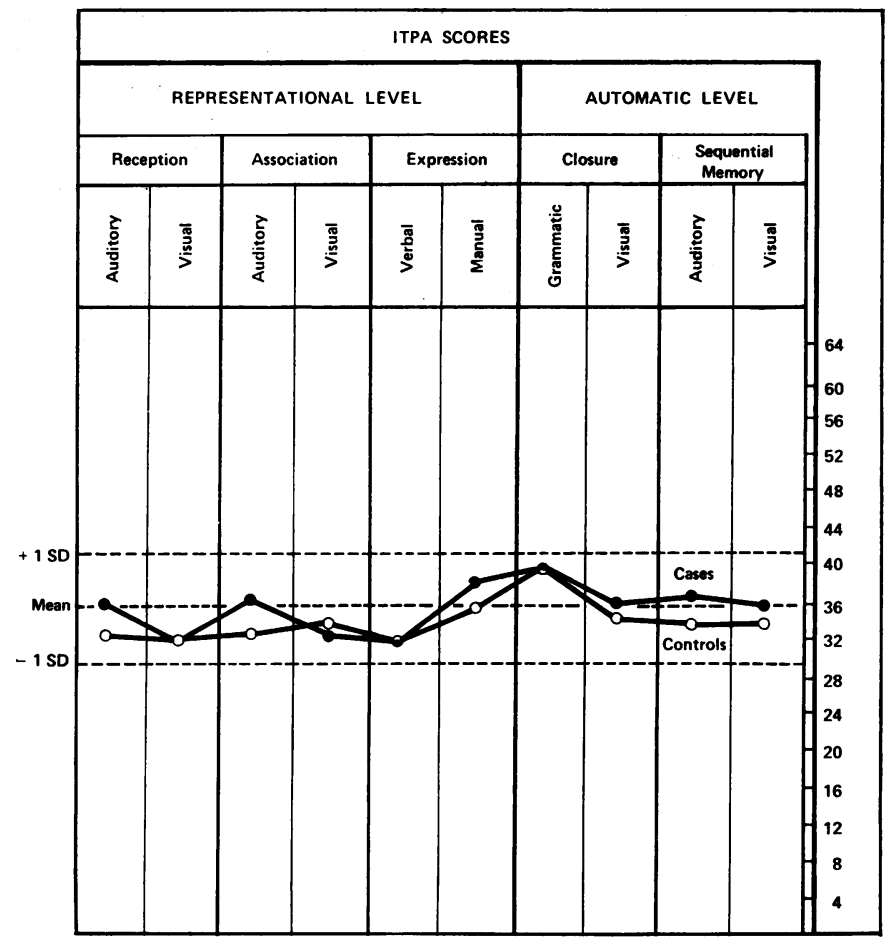

Fig. 1 Illinois Test of Psycholinguistic Abilities Subtest scores for cases and controls.

controls. The ITPA is designed to test the psychological functions which operate in communication activities. The subtests show defects in (a) 3 processes of communication, i.e. receptive, expressive, and associative; (b) 2 levels of language organization, the automatic (e.g. role learning, speed of perception), and the representational level which requires the more complex mediating process of utilizing symbols; (c) 2 channels of language input, i.e. auditory and visual, and output, i.e. verbal and motor.

Comparison of the individual's score with the average for his peer group is possible, and a standard score is calculated for each subtest. An overall estimate called the Composite Psycholinguistic Age is also derived and from this the Psycholinguistic Quotient (PLQ) is calculated.

$$
\text { PLQ }=\frac{\text { Psycholinguistic age }}{\text { Chronological age }} \times 100 \text {. }
$$

PLQ is comparable to, but not identical with, intelligence quotient (IQ). A PLQ of $<70$ represents a significant degree of mental retardation.

In the Bender-Gestalt Test, protocols were scored using the Koppitz (1963) developmental scoring system. Poor performance on this test indicates difficulties in visuo-motor co-ordination or visual perception. An individual's score can be compared with the norm for his age group to ascertain whether impairment is significant enough to indicate organic brain damage.

\section{Results}

The follow-up of the $\mathbf{4 3}$ survivors is shown in Table 4. At the time of study 10 children could not be

Table 4 Follow-up of the 43 survivors

No. \% of total No. with significant handicap

\begin{tabular}{lrrl}
\hline No follow-up & 3 & 7 & - \\
Incomplete follow-up & 9 & 21 & 0 \\
Examined in study & 31 & 72 & 2 \\
with controls & 29 & & 0 \\
without controls & 2 & &
\end{tabular}

traced. Of these, 5 are known to have attended normal school with no history of convulsions and no neurological abnormalities when examined at the Royal Aberdeen Children's Hospital at ages ranging from 3 to 7 years. One was considered normal at 3 years when his family emigrated, and another was assessed as normal before successful adoption in infancy. No direct information is available for the 3 
remaining children, but they are all unknown to the regional handicap services and the Royal Aberdeen Children's Hospital which is the sole paediatric centre for the North-east of Scotland. The parents of 2 children refused to take part in the study. Both children are making normal school progress and had no neurological abnormalities when admitted to the Royal Aberdeen Children's Hospital aged 10 years and 6 years.

Controls of sufficiently low birthweight could not be found for 2 cases. 1 boy (birthweight $1080 \mathrm{~g}$ at 27 weeks' gestation) at age $5 \frac{1}{2}$ years had no neurological abnormalities and a PLQ of 109. The second boy (birthweight $1245 \mathrm{~g}$ at 28 weeks' gestation) aged 10 years had no neurological abnormalities and a PLQ of 100. Both children had a Bender-Gestalt performance which was below average but within normal limits (see Fig. 2).

Neurological examination. Table 5 shows the overall neurological ratings for the cases and their controls.

Table 5 Results of neurological examination

\begin{tabular}{lllrc}
\hline Category* & $\begin{array}{l}\text { Neurological } \\
\text { abnormalities }\end{array}$ & Handicap & $\begin{array}{l}\text { Cases } \\
(n=29)\end{array}$ & $\begin{array}{l}\text { Controls } \\
(n=29)\end{array}$ \\
\cline { 5 - 5 } 1 & None & None & 19 & 23 \\
2 & Doubtful & None or slight & 7 & 6 \\
3 & Definite & None or slight & 1 & 0 \\
4 & Definite & Moderate or severe & 2 & 0
\end{tabular}

*See 'Patients and methods'.

7 cases and 6 controls showed doubtful neurological abnormalities which included hyperactive behaviour, minor degrees of motor dysfunction, squints, articulatory speech defects, and febrile convulsions. Of the 3 cases with definite neurological abnormality, 1 has bilateral nerve deafness with a $50 \mathrm{db}$ loss from 4000 $8000 \mathrm{~Hz}$ but no significant handicap in that she is making average progress in a normal school without the use of a hearing aid. 2 are severely handicapped by spastic quadriplegia and epilepsy and are presented in separate case reports.

Psychological assessment. Of the 31 cases seen, only 2 (Cases 3 and 4 below) were considered untestable. Their matched controls were normal. Of the remaining cases, 3 were excluded from statistical analysis, the 2 for whom no controls were available, and a $9 \frac{1}{2}$-year-old boy whose test results were unreliable due to noncooperation but whose school performance is satisfactory.

A paired ' $t$ ' test was carried out on the PLQ scores of the 26 complete pairs. This gave a mean difference (control-case) of $1 \cdot 23$ which did not differ significantly from zero $(t=0.4, P>0.05)$. The distribution of

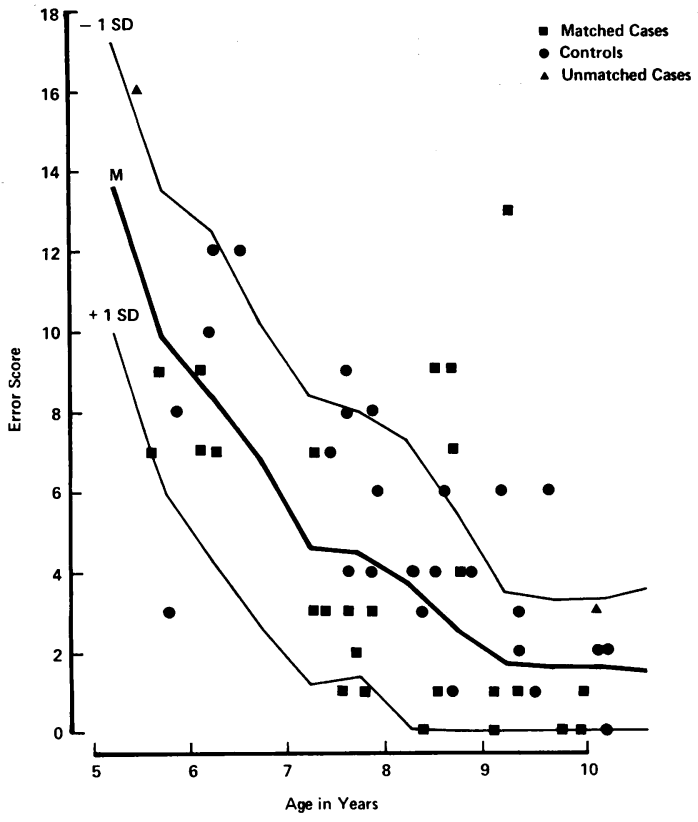

Fig. 2 Distribution of case and control scores on Bender-Gestalt Test in relation to Koppitz mean and standard deviation curves.

case and control scores, and the mean values for cases and controls are shown in Tables 6 and 7

Table 6 Distribution of case and control psycholinguistic quotient (PLQ) scores

\begin{tabular}{lcc}
\hline$P L Q$ & $\begin{array}{l}\text { Cases } \\
(n=26)\end{array}$ & $\begin{array}{l}\text { Controls } \\
(n=26)\end{array}$ \\
\hdashline$<70$ & 0 & 0 \\
$70-85$ & 6 & 6 \\
$86-100$ & 10 & 15 \\
$101-115$ & 9 & 5 \\
$116-130$ & 1 & 0 \\
$>130$ & 0 & 0 \\
\hline
\end{tabular}

Table 7 Mean PLQ scores for cases and controls

\begin{tabular}{lcll}
\hline & Mean PLQ & $S D$ & $S E$ \\
\hline Cases $(n=26)$ & $96 \cdot 3$ & $12 \cdot 7$ & $2 \cdot 5$ \\
Controls $(n=26)$ & $94 \cdot 5$ & $11 \cdot 2$ & $2 \cdot 2$ \\
\hline
\end{tabular}

respectively. When paired differences in PLQ were plotted against social class, gestational age, and birthweight there were no statistically significant correlations.

Comparison of cases and controls on the 10 separate subtests of the ITPA showed no significant differences in the mean scores of the 2 groups, 
although, as shown in Fig. 1, the cases performed better on the auditory association subtest. The mean scores of case and control groups were identical for 3 subtests. Score distribution for the automatic and representational levels of organization did not differ significantly in the 2 groups. On a graph of BenderGestalt test performance of cases and controls plotted with the standard age curve (Fig. 2), the cases were significantly more often below the curve, i.e. showed better than average performance more often than the controls (cases $73 \%$ below, controls $31 \%$ below, $\chi^{2}=9 \cdot 3, \mathrm{P}=0 \cdot 01$ ).

It is noteworthy that the 2 children (Cases 1,2 , Table 8) with a 1-minute Apgar score of 0 achieved

Table 8 Psychological assessment of the 2 cases with 1 minute Apgar score of 0

\begin{tabular}{lcc}
\hline Test & Case & Control \\
\hline ITPA PLQ & 119 & \\
Case 1 & 111 & 82 \\
Case 2 & 3 & 96 \\
Bender-Gestalt Score & 1 & 4 \\
Case 1 & 3 \\
Case 2 & & \\
\hline
\end{tabular}

ITPA = Illinois Test of Psycholinguistic Ability .

an above average PLQ score which was higher than that of their controls, and also a better BenderGestalt performance.

Incidence of serious mental and neurological handicap. As shown in Table 9, 2 cases were both severely

Table 9 Incidence of serious mental and neurological handicap

\begin{tabular}{lll}
\hline & $\begin{array}{l}\text { Cases } \\
(n=29)\end{array}$ & $\begin{array}{l}\text { Controls } \\
(n=29)\end{array}$ \\
\hline No serious mental or neurological handicap & 27 & 29 \\
Neurological handicap alone & 0 & 0 \\
Mental handicap alone (PLQ <70) & 0 & 0 \\
Mental and neurological handicap (Cases 3, 4) & 2 & 0 \\
\hline
\end{tabular}

physically and mentally handicapped (see case reports). 27 out of 29 cases $(93 \%)$, and all the controls, had no serious handicap.

In an attempt to identify discriminating factors prognostic for the occurrence of serious handicap after severe birth asphyxia the following possible influences were examined: birthweight, gestational age, social class, duration of clinical fetal distress, 1minute Apgar score of 0, numerical value of Apgar score at 5 minutes (within the range 1-3), cardiac arrest, time taken to sustain regular spontaneous respiration, and abnormal postnatal behaviour. All these factors except for the last two were found to be of no predictive value. The relationship between time taken to establish regular spontaneous respiration and the occurrence of serious handicap approached significance at the $10 \%$ level. A strongly positive correlation existed between the occurrence of definite neurological abnormality and the number of abnormal postnatal behaviour features shown by each case (correlation coefficient $=0.63, \mathrm{P}<0.01$ ).

\section{Case reports}

Case 3 was delivered by emergency caesarean section after a severe accidental haemorrhage at 35 weeks' gestation and weighed $2475 \mathrm{~g}$. The fetal heart was $>170 /$ min for 1 hour before delivery. Apgar score was 1 at 1 and 5 minutes. He received intravenous glucose and sodium bicarbonate, and intermittent positive pressure ventilation via endotracheal tube until regular respiration was established at 18 minutes of age. Initially he was hypothermic and severely hypotonic with a weak high-pitched cry. From 12 hours of age till 5 days he had frequent convulsions. At 3 days he underwent laparotomy and colostomy for intestinal obstruction due to biopsy-proven Hirschsprung's disease. He required tube feeding for 3 weeks. Now, at the age of $9 \frac{3}{4}$ years he is epileptic, microcephalic, blind, severely mentally retarded, and quadriplegic.

Case 4 was a spontaneous vaginal delivery at 41 weeks' gestation weighing $3000 \mathrm{~g}$. 30 minutes before delivery the fetal heart dropped to $88 / \mathrm{min}$, and at birth the cord was tightly wrapped round his neck. Apgar score was 2 at 1 and 5 minutes. Although given intermittent positive pressure ventilation via endotracheal tube and intravenous sodium bicarbonate immediately, he responded poorly and took 60 minutes to establish regular respiration. He was hypothermic, markedly hypotonic with absent Moro reflex, and weak high-pitched cry. He convulsed intermittently for the first 5 days and required tube feeding for 2 weeks. Now, at age 7 years he is severely mentally retarded, epileptic, and quadriplegic.

\section{Discussion}

Those who care for severely asphyxiated newborn infants are sometimes faced with difficult decisions about the extent to which resuscitative measures should be applied. On the one hand there is concern that vigorous and prolonged resuscitation could lead to the survival of a severely handicapped child who might otherwise have died; on the other hand nonintervention might deny such an infant the chance of a normal or near normal life. Because of this dilemma, we felt it would be valuable to review our 
experience of resuscitation of very severely asphyxiated neonates.

To examine the impact of perinatal asphyxia on development and learning capacity, studies of school age children are essential. Studies of younger children are useful but may not uncover subtle deficiencies in learning skills. The longer the follow-up period, however, the more out of date becomes the perinatal care received. Fetal heart monitoring and scalp $p \mathrm{H}$ measurements were not yet in use. The cases in this study were treated in a modern special care unit, but very early introduction of milk feeds and monitoring for asymptomatic hypoglycaemia were not standard practice at that time. Many adverse factors in the perinatal period and later childhood influence eventual neurological and psychological status, making it difficult to identify the part played by birth asphyxia alone. Several of our cases had mechanically traumatic deliveries, but none had serious hyperbilirubinaemia, meningitis, or later head injury.

An unfortunate result of the long follow-up period is that 3 children ( $7 \%$ of total) have been completely lost, though there is no reason to believe that their removal from the area was related to the occurrence of handicap.

In any long-term study involving intellectual assessment, environmental and genetic influences must be considered. Ideally, sibs should be used as controls, but as only 2 cases had sibs of suitable sex, birthweight, gestational age, and Apgar scores, controls had to be taken from different families of the same social class.

Despite these difficulties our results are encouraging. Apart from 2 severely mentally and physically handicapped children all the survivors examined ( $72 \%$ of the total possible) are leading normal lives and attending ordinary school. Their intellectual performance is in fact slightly, though not significantly, better than that of carefully matched controls. Information about a further $21 \%$ of the total, not examined in the study, indicates that they too are making normal progress. Cases and controls were drawn from the total population of the city and suburbs of Aberdeen, whose social class distribution is similar to that of Scotland as a whole.

There is an extensive literature on the long-term sequelae of birth asphyxia. Comparison between studies is difficult because of differences in population, nursery practices, and interpretation of abnormality at follow-up. The wide variation in criteria used to define birth asphyxia creates a particular problem in this respect. James (1960) has shown that infants with a 1-minute Apgar score of $<4$ have biochemical evidence of severe asphyxia. It is reasonable to assume that our cases were at least as severely affected.
Drage et al. (1966), in the Collaborative Project of the National Institute of Neurological Diseases and Blindness reported that $7.4 \%$ of infants with a 5-minute Apgar score of $<4$ had neurological abnormalities when examined at 1 year of age. In the present study 3 out of $29(10.3 \%)$ infants with a 5 -minute Apgar score of $<4$ had definite neurological abnormalities. Drage et al. (1969) found no consistently significant mean IQ score difference between 4-year-old children with a 5-minute Apgar score of 8-10 and a 5-minute Apgar score of 0-6 except in isolated instances, when controlled by maternal education, birthweight, and race.

In an earlier study of Aberdeen schoolchildren who survived varying degrees of birth asphyxia defined by the times taken to first gasp, regular respiration, and first cry, and whose birthweight was $>2500 \mathrm{~g}$, Fraser and Wilks (1959) found no lowering of IQ and only doubtful impairment of some motor functions and perceptions as compared with controls. Millar and Neligan (1968) found a low IQ in 5-year-old Newcastle children only when onset of regular respiration had been delayed beyond 30 minutes after birth.

We were reassured to find that our 2 successfully resuscitated, apparently stillborn children were functioning normally with PLQs of 119 and 111 . Scott (1974) also reports a favourable outcome for 6 out of 7 babies with a 1-minute Apgar score of 0 born at the Hammersmith Hospital in 1966-71 and followed for 2-7 years.

Lilienfeld and Pasamanick (1955) postulated that antenatal or perinatal insults might produce 'a continuum of reproductive casualty with a lethal component consisting of abortion, stillbirths, and neonatal deaths, and a sublethal component consisting of cerebral palsy and perhaps other related conditions'. Our study provides no evidence to support the concept of a continuous gradation of the severity of sequelae in survivors of birth asphyxia, but rather points to an all-or-none effect. For the most part cases are indistinguishable from controls. Where detrimental effects exist these are extreme. Similarly, the results obtained by Benaron et al. (1960) suggested that birth asphyxia does not produce a generalized lowering of function but rather overt abnormality in isolated cases.

Brown et al. (1974) found that of asphyxiated newborn infants showing one or more of certain symptoms, i.e. feeding difficulties, apnoeic and/or cyanotic attacks, persistent vomiting, convulsions, hypothermia, and a high-pitched cerebral cry, $63 \%$ had neurological defects when examined at a mean age of 21 months. $12 \%$ were classified as severely handicapped, and $14 \%$ as handicapped. In our study the total number of a similar group of ab- 
normal features shown by each case was highly significant in predicting the occurrence of serious handicap. However, as some overlap occurred in the number of features shown by individual handicapped and nonhandicapped cases this was not a reliable guide to outcome in the indidivual case. Moreover, this information is not available at the time of deciding the extent of resuscitative efforts. While the relationship between the length of times taken to establish sustained spontaneous respiration and the occurrence of serious handicap approached significance at the $10 \%$ level, there was again some overlap in the times taken to establish sustained respiration by individual handicapped and nonhandicapped children.

The occurrence of cardiac arrest did not influence outcome in our survivors but in each case the duration was short. Our experience is in keeping with that of Steiner and Neligan (1975) who found that if cardiac arrest was of less than 5 minutes' duration and if regular spontaneous respiration was established within 30 minutes thereafter, the prognosis appeared to be uniformly good.

This study indicates that the quality of life enjoyed by the vast majority of survivors of severe birth asphyxia justifies a vigorous approach to resuscitation. It was not possible to identify any factor that predicted with certainty the severe degree of handicap which unfortunately followed in a few individuals.

We thank Dr. C. Robb and Dr. D. Choudhury of the Community Child Health Service for access to school medical records; Dr. G. Hems for statistical advice; Mrs. S. Todd for secretarial help; and Professor A. G. M. Campbell for reviewing the manuscript. Fig. 1 is reproduced by permission of the University of Illinois Press. The study was supported by a grant from the Grampian Health Board.

\section{References}

Apgar, V. (1953). A proposal for a new method of evaluation of the newborn infant. Current Researches in Anesthesia and Analgesia, 32, 260-267.

Benaron, H. B. W., Tucker, B. E., Andrews, J. T., Boshes, B., Cohen, J., Fromm, E., and Yacozynski, G. K. (1960). Effect of anoxia during labor and immediately after birth on the subsequent development of the child. American Journal of Obstetrics and Gynecology, 80, 1129-1142.

Bender, L. (1946). Instructions for the Use of Visual Motor Gestalt Test. American Orthopsychiatric Association, New York.
Brown, J. K., Purvis, R. J., Forfar, J. O., and Cockburn, F. (1974). Neurological aspects of perinatal asphyxia. Developmental Medicine and Child Neurology, 16, 567-580.

Drage, J. S., Kennedy, C., Berendes, H., Schwarz, B. K., and Weiss, W. (1966). The Apgar score as an index of infant morbidity. Developmental Medicine and Child Neurology, 8, 141-148.

Drage, J. S., Berendes, H. W., and Fisher, P. D. (1969). Perinatal Factors Affecting Human Development, p. 222. Scientific Publication No. 185. Pan-American Health Organization, Washington.

Dweck, H. S., Huggins, W., Dorman, L. P., Saxon, S. A., Benton, J. W., and Cassady, G. (1974). Developmental sequelae in infants having suffered severe perinatal asphyxia. American Journal of Obstetrics and Gynecology, 119, 811-815.

Fraser, M. S., and Wilks, J. (1959). The residual effects of neonatal asphyxia. Journal of Obstetrics and Gynaecology of the British Empire, 66, 748-752.

James, L. S. (1960). Acidosis of the newborn and its relation to birth asphyxia. Acta Paediatrica Scandinavica, 49, Suppl. $122,17-28$.

Kirk, S. A., McCarthy, J. J., and Kirk, W. D. (1961). The Illinois Test of Psycholinguistic Abilities. University of Illinois Press, Urbana, Illinois.

Koppitz, E. M. (1963). The Bender Gestalt Test for Young Children. Grune and Stratton, New York.

Lilienfeld, A. M., and Pasamanick, B. (1955). The association of maternal and fetal factors with the development of cerebral palsy and epilepsy. American Journal of Obstetrics and Gynecology, 70, 93-101.

Millar, D. G., and Neligan, G. (1968). The Newcastle maternity survey and survey of child development. Journal of Obstetrics and Gynaecology of the British Commonwealth, 75, 481-482.

Paine, R. S., and Oppé, T. E. (1966). Neurological Examination of Children. Heinemann, London.

Richards, F. M., Richards, I. D. G., and Roberts, C. J. (1968). The influence of low Apgar rating on infant mortality and development. Studies in Infancy, pp. 84-88. Clinics in Developmental Medicine No. 27. Heinemann, London.

Rutter, M., Graham, P. and Yule, W. (1970). A Neuropsychiatric Study in Childhood. Clinics in Developmental Medicine No. 35-6. Heinemann, London.

Scott, H. (1974). Outcome of severe birth asphyxia. Archives of Disease in Childhood, 49, 820.

Sheridan, M. D. (1958). Simple clinical hearing-tests for very young or mentally retarded children. British Medical Journal, 2, 999-1004.

Sheridan, M. D. (1960). Vision screening of very young or handicapped children. British Medical Journal, 2, 453-456.

Steiner, H., and Neligan, G. (1975). Perinatal cardiac arrest. Archives of Disease in Childhood, 50, 696-702.

Thomson, A. M., Billewicz, W. Z., and Hytten, F. E. (1968). The assessment of fetal growth. Journal of Obstetrics and Gynaecology of the British Commonwealth, 75, 903-916.

Correspondence to Dr. Alison J. Thomson, Paediatric Department, Peel Hospital, Galashiels, Selkirkshire, Scotland. 